\title{
Effects of Olanzapine and Clozapine on Depression and Anxiety in Mice: Alterations in Brain Neurotrophic Factor Expression Levels
}

\author{
Esen Gümüşlü' (D), Oğuz Mutlu² (1) \\ 'Department of Medical Genetics, Kocaeli University School of Medicine, Kocaeli, Turkey \\ 2Department of Medical Pharmacology, Kocaeli University School of Medicine, Kocaeli, Turkey
}

Cite this article as: Gümüşlü E, Mutlu O. Effects of Olanzapine and Clozapine on Depression and Anxiety in Mice: Alterations in Brain Neurotrophic Factor Expression Levels. JAREM 2019; 9(2): 97-101.

\begin{abstract}
Objective: Schizophrenia, is an important brain neurodevelopmental disorder observed in $1 \%$ of the global population. Classical antipsychotics cause extrapyramidal side effects and are less effective on the negative symptoms of schizophrenia. New-generation atypical antipsychotics have been developed as alternatives to typical antipsychotics for more effective on negative symptoms of schizophrenia such as mood and memory disorders or safer therapy. Olanzapine and clozapine are new atypical antipsychotics that are frequently used in clinics.

Methods: Effects of olanzapine and clozapine on depression and anxiety in the forced swimming (FST) and elevated plus maze (EPM) test were examined in mice. Since there is a growing interest in the role of neutrophins in the pathophysiology of schizophrenia, the effects drugs on the expression levels of brain neurotrophic factors (BDNF, CREB, NGF, synapsin and FGF2) in the hippocampus of mice were also investigated. Mice were treated chronically and intraperitoneally with olanzapine ( 1 and $2 \mathrm{mg} / \mathrm{kg}$ ) or clozapine (1.25 and $2.5 \mathrm{mg} / \mathrm{kg})$ for 10 days and 60 and 30 minutes respectively before FST and EPM tests on the $11^{\text {th }}$ day.

Results: In the FST test, clozapine $(2.5 \mathrm{mg} / \mathrm{kg} ; \mathrm{p}<0.05)$ significantly decreased immobility time while olanzapine (1ve $2 \mathrm{mg} / \mathrm{kg} ; \mathrm{p}>0.05)$ had no significant effect on this parameter. In the EPM test, olanzapin $(2 \mathrm{mg} / \mathrm{kg} ; \mathrm{p}<0.01)$ and clozapine $(1.25 \mathrm{ve} 2.5 \mathrm{mg} / \mathrm{kg} ; \mathrm{p}<0.01 \mathrm{and} p<0.05$ respectively) significantly increased both \% time spent in open arms $(p<0.001)$ and \% open arm entries $(p<0.01)$. Clozapine up-regulated the expression of BDNF, CREB, NGF synapsin and FGF2 in the mice hippocampus. Olanzapine up-regulated the expression of NGF, synapsin and FGF2 but it down-regulated the expression of BDNF and CREB.

Conclusion: Clozapine seems to possess superior effects compared to olanzapine on negative semptoms of schizophrenia since it up-regulates more neurotrphic factors than olanzapine in the brain.
\end{abstract}

Keywords: Antipsychotics, behaviour, neurotrophic factors

\section{INTRODUCTION}

Schizophrenia is a neurodevelopmental disorder of the brain, which affects $1 \%$ of the population. Antipsychotic drugs are used in conditions, such as schizophrenia, psychotic disorders, and psychotic depression. The classic antipsychotic drugs, such as haloperidol, cause extrapyramidal side effects and have low effectiveness on the negative symptoms of schizophrenia; therefore, atypical antipsychotic drugs have been developed as an alternative to the typical antipsychotics to ensure more effective and safe treatment (1).

Olanzapine is an atypical antipsychotic drug that is widely used in the treatment of schizophrenia and other psychoses (2). The atypical antipsychotics show less selective activity on various neurotransmitter receptors (i.e., they show moderate antagonist activity on $5 \mathrm{HT}_{2}$ receptors and less and equal antagonistic activity on dopamine $D_{1}, D_{2}$ and $\alpha_{1}$ receptors) (3). In radioligand binding studies, olanzapine has shown a high affinity for many neuronal receptors, including dopamine $\mathrm{D}_{1^{\prime}} \mathrm{D}_{2^{\prime}} \mathrm{D}_{4^{\prime}} 5 \mathrm{HT}_{2 \mathrm{~A}^{\prime}} 5 \mathrm{HT}_{2 \mathrm{C}^{\prime}}$ $\alpha_{1}$-adrenergic, histamine $\mathrm{H}_{1}$, and muscarinic receptors (4). Clozapine is a reference drug for atypical antipsychotics and is used particularly in cases that are resistant to other antipsychotics. It acts on many receptors in the brain, including dopamine $D_{4}$, serotonin $5 \mathrm{HT}_{2 \mathrm{~A}}$ and $5 \mathrm{HT}_{2 \mathrm{C}^{\prime}}$ norepinephrine $\alpha_{1}$ and $\alpha_{2}$, acetylcholine, muscarinic, and histamine $\mathrm{H}_{1}$ receptors (5).

The effect of drugs on mood is particularly important in the treatment of symptoms, such as depression and anxiety, associated with schizophrenia and psychosis and in improvement of patients' quality of life. Considering this situation, understanding the ef- 
fects of antipsychotic drugs on depression and anxiety would be an important approach with regard to evaluating the clinical utility of drugs. In this study, we aimed to investigate the effect of the atypical antipsychotics olanzapine and clozapine on depression and anxiety in a forced swim test (FST) and elevated plus maze (EPM) test. In recent years, the role of neurotrophic factors in the pathophysiology of schizophrenia has been questioned. In diseases, such as depression and schizophrenia, the mRNA levels of brain-derived neurotrophic factor (BDNF) and cyclic adenosine monophosphate response element binding protein (CREB) are reduced, and the structure of neurons is disrupted and cell death is observed. The fibroblast growth factor (FGF2), a trophic factor commonly found in the adult brain, activates CREB and regulates cell proliferation by phosphorylating CREB. FGF2 also plays a role in the synaptic plasticity and psychoactive drugs can alter its expression. Also, nerve growth factor (NGF) has been reported to play a role in several biological events. Since synapsin is crucial in synaptic transmission and neuronal development, it plays an important role in hippocampal behavior (6-8). A chronic therapy with antipsychotics and antidepressants increases the level of neurotrophic factors, reduces cell death in neurons, and has positive effects on the synaptic plasticity and neurogenesis (911). Some atypical antipsychotics have been reported to increase neurogenesis. Therefore, we investigated the effect of chronically administered olanzapine and clozapine in rats on the brain neurotrophic factors in the hippocampus using the quantitative real time-polymerase chain reaction (RT-PCR) method.

\section{METHODS}

\section{Experimental Animals}

In this study, 7-8-week-old male of the same lineage BALB/c ByJ rats were used. The rats were kept in the laboratory for 2 weeks before initiating the experiment (12 hours light and 12 hours dark cycle; lights turned on at 07:00 hours; temperature $=21 \pm 1^{\circ} \mathrm{C}$ ). Animals were provided with ad libitum food and water. Approval from the ethics committee for all the procedures mentioned was taken on 1/6/2014, and the European Community Council Directive (86/609/EEC) was carried out in line with animal ethics.

\section{Experimental Groups and Drug Application}

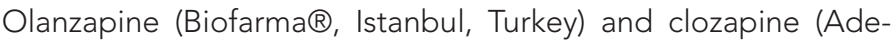
$\mathrm{ka} \otimes$, Samsun, Turkey) were dissolved in saline containing a small amount of $0.1 \mathrm{M}$ hydrochloric acid $(\mathrm{HCl})$. The drugs were freshly prepared daily and administered as $0.1 \mathrm{~mL} / 10 \mathrm{~g}$ of body weight of rats. The same volume of solvent was administered to the control groups. Olanzapine ( 1 and $2 \mathrm{mg} / \mathrm{kg} ; \mathrm{n}=9$ and 10 , respectively), clozapine ( 1.25 and $2.5 \mathrm{mg} / \mathrm{kg} ; \mathrm{n}=8$ and 10 , respectively) or solvent (a small amount of $0.1 \mathrm{M} \mathrm{HCl}$ in saline $\mathrm{n}=10$ ) were administered to BALB/c rats intraperitoneally and chronically for 10 days and administered 60 and 30 min before FST and EPM test, respectively, on the eleventh day. Another group of rats that was administered chronic olanzapine $(2 \mathrm{mg} / \mathrm{kg} ; \mathrm{n}=7)$ and clozapine $(2.5 \mathrm{mg} / \mathrm{kg} ; \mathrm{n}=7)$ for 14 days but not exposed to behavioral experiments was sacrificed, and the hippocampal BDNF, CREB, NGF, synapsin, and FGF2 gene expression levels were evaluated. The drug doses were selected according to previous behavioral and neurochemical studies $(12,13)$.

\section{Forced Swim Test}

Rats were placed alone in Plexiglas ${ }^{\circledR}$ cylinders (height $25 \mathrm{~cm}$ and diameter $10 \mathrm{~cm}$ ) containing water up to a height of $10 \mathrm{~cm}$ at $23^{\circ} \mathrm{C}-25^{\circ} \mathrm{C}$ and were held there for 6 minutes. Since this was an inescapable situation, the animals quickly became immobile, stood on top of the water in a vertical position, and made small movements that only allowed them to keep their heads above the water. The inactivity time in the last 4 minutes of the 6-minute test period was recorded (14).

\section{Elevated Plus Maze Test}

The anxiety-related behavior is measured using the EPM test. The experiments were performed in a light, semi-sound-permeable, desk-lit (80 lux) room. The labyrinth was made of wood and was at a height of $40 \mathrm{~cm}$ from the ground, and its two open (29 $\mathrm{cm}$ long $\times 5 \mathrm{~cm}$ wide) and two closed arms (with walls at $29 \times 5 \times 15$ $\mathrm{cm}$ high) crossed each other to form a $5 \mathrm{~cm}^{2}$ center. Each rat was placed in the center of the labyrinth facing one of the open arms and then allowed to examine the labyrinth. The open arm activity is evaluated as follows: (1) the time spent in the open field is expressed as the percentage of the total time spent in the maze (300 s) and (2) the total number of entries in open arms is expressed as the percentage of the total number of entries in both open and closed arms.

\section{RNA Isolation and Quantitative Real Time-Polymerase Chain Reaction}

The total RNA was isolated from the brain tissue of each rat using RNeasy Mini Kit $($ (QIAGEN, Valencia, CA, USA) and treated with

\section{Table 1. Primer sequences of the genes}

\begin{tabular}{|c|c|}
\hline GENE & PRIMER SEQUENCE \\
\hline $\begin{array}{l}\text { Beta-2 } \\
\text { microglobulin-F }\end{array}$ & $5^{\prime}$ TGA CTT TGT CACAGC CCA AGA TA 3 \\
\hline $\begin{array}{l}\text { Beta-2 } \\
\text { microglobulin-R }\end{array}$ & $5^{\prime}$ AAT CCA AAT GCG GCA TCT TC 3' \\
\hline BACT-F & $5^{\prime}$ AGC CAT GTA CGT AGC CAT CCA 3' \\
\hline BACT-R & 5' TCT CCG GAG TCC ATC ACA ATG 3' \\
\hline CREB-F & 5' AGC TGG CCT GTC CCA CTG CT 3' \\
\hline CREB-R & $5^{\prime}$ ACC ATT CTG AAC ACA AAG CAG CCA3' \\
\hline BDNF-F & 5' GCC CAA CGA AGA AAA CCA TAA3' \\
\hline BDNF-R & 5' GGA GGC TCC AAAGGC ACT T 3' \\
\hline NGF-F & 5'- AGT TाT GGC CTG TGG TC- 3' \\
\hline NGF-R & 5'- CTC ACT GCG GCC AGT ATA- 3' \\
\hline FGF2-F & 5'- TGT TTC TTC TाT GAA CGA CT-3' \\
\hline FGF2-R & 5'- TCA GCT CTT AGC AGA CAT TGG A-3' \\
\hline Synapsin 1-F & 5'- ATT GCA AGT GTT GTG GCA C -3' \\
\hline Synapsin 1-R & 5'- GCC TTG TAG TTC TGC CCA AT -3' \\
\hline
\end{tabular}


DNase I. The cDNA synthesis was performed using the RevertAid First Strand $®$ cDNA synthesis kit (Fermentas Inc., MD, USA). Quantitative RT-PCR was performed as previously mentioned $(15,16)$. Standard curves were obtained using serial dilutions of the beta-globulin gene. The specific primers for the studied genes (Table 1) were obtained from Integrated DNA Technologies (IA, USA) and IONTEK Inc. (Merter, Istanbul, Turkey). The BACT housekeeping gene was used to normalize the obtained gene expression values. The gene expression levels were calculated using the Relative Expression Software Tool (REST) program. The change in CREB, BDNF, NGF, synapsin, and FGF2 gene expression levels was determined by comparing with the control group.

\section{Statistical Analysis}

FST and EPM test results were evaluated using the one-way ANOVA test, and when significant differences were found, post-hoc Tukey's test was used. The statistical evaluation of CREB, BDNF, NGF, synapsin, and FGF2 gene expressions was performed using the REST program. Data were expressed as fold changes according to the control values. Data were expressed as mean \pm standard deviation. A p value $<0.05$ was considered statistically significant.

\section{RESULTS}

\section{Effects of Olanzapine and Clozapine on Depression-Like Be- havior in the Forced Swim Test}

There was a significant difference between the groups when the effects of olanzapine and clozapine on the time of inactivity in the

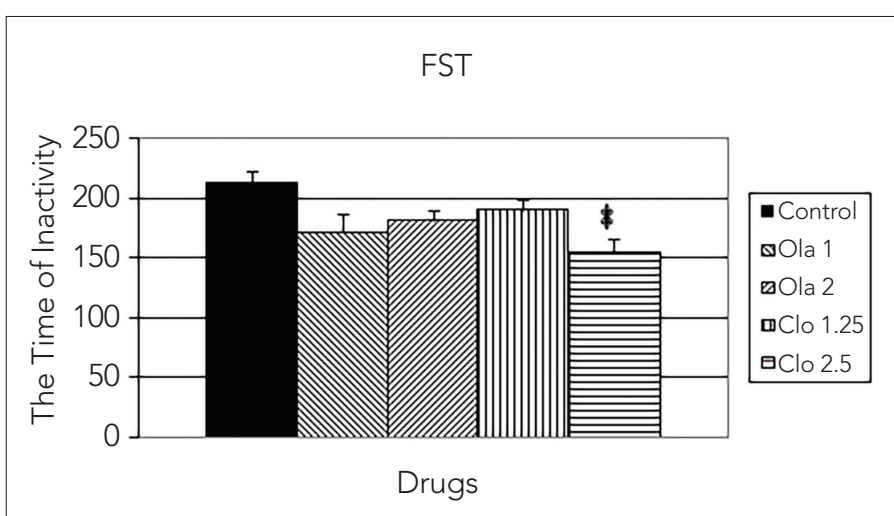

Figure 1. Effects of olanzapine ( 1 and $2 \mathrm{mg} / \mathrm{kg} ; \mathrm{n}=9,10$ respectively) and clozapine ( 1.25 and $2.5 \mathrm{mg} / \mathrm{kg} ; n=8,10$, respectively) administered intraperitoneally for 10 days on the time of inactivity in the FST. Data are expressed as mean \pm standard deviation

${ }^{*} p<0.01$, compared to the control group

(FST: force swim test; Clo.: clozapine; Ola.: olanzapine)
FST (F [4.42] =3.88; $p=0.0090$; Figure 1) were evaluated. Clozapine $(2.5 \mathrm{mg} / \mathrm{kg} ; \mathrm{p}<0.01)$ had significantly shortened the inactivity time compared to the control group, whereas olanzapine showed no significant effect (Figure 1).

\section{Effects of Olanzapine and Clozapine on Anxiety in Elevated Plus Maze Test}

There was a significant difference between the groups when the effect of olanzapine and clozapine on the percentage of time spent in open arms was evaluated in the EPM text $(F[4.42]=12.55$; $\mathrm{p}<0.0001$; Figure 2a). Both olanzapine (2 mg/kg, $\mathrm{p}<0.001)$ and clozapine (1.25 and $2.5 \mathrm{mg} / \mathrm{kg} ; \mathrm{p}<0.001, \mathrm{p}<0.01$, respectively) significantly increased the percentage of time spent in the open arms (Figure 2a). When the effect of olanzapine and clozapine on the percentage of open arm access was evaluated, there was a significant difference between the groups ( $F[4.42]=8.25$; $\mathrm{p}<0.0001$; Figure 2b). Both olanzapine (2 mg/kg, $\mathrm{p}<0.001)$ and clozapine (1.25 and $2.5 \mathrm{mg} / \mathrm{kg} ; \mathrm{p}<0.001, \mathrm{p}<0.01$, respectively) significantly increased the percentage of open arm access in the EPM test (Figure 2b).

\section{Effect of Olanzapine and Clozapine on Hippocampal Neurotrophic Factor Gene Expression Levels}

Clozapine significantly increased the gene expression levels of rat hippocampal BDNF, CREB, NGF, synapsin, and FGF2, which are members of the neurotrophin family compared to the control group. While olanzapine significantly increased NGF, synapsin, and FGF2 gene expression levels, BDNF and CREB gene expression levels were decreased significantly compared to the control group. The primer sequences of the genes studied are shown in Table 1, and the level of gene expression in each group is shown in Table 2.

\section{DISCUSSION}

According to our findings, clozapine $(2.5 \mathrm{mg} / \mathrm{kg})$ reduced the time of inactivity in FST, whereas olanzapine (1 and $2 \mathrm{mg} / \mathrm{kg}$ ) did not show a significant effect. In EPM, both olanzapine $(2 \mathrm{mg} / \mathrm{kg})$ and clozapine (1.25 and $2.5 \mathrm{mg} / \mathrm{kg}$ ) significantly increased the percentage of time spent in the open arms and the percentage of open arm access. According to the genetic analysis, clozapine significantly increased the levels of BDNF, CREB, NGF, synapsin, and FGF2 gene expression in the rat hippocampus, while olanzapine increased NGF, synapsin, and FGF2 expression levels and decreased BDNF and CREB levels.

Schizophrenia is a brain disease that has positive and negative symptoms and causes changes in the neurotransmitters of the brain, changes in the structure and function of neuronal den-

Table 2. Effects of olanzapine and clozapine on the gene expression levels of neurotrophic factors in rats. The drugs were administered intraperitoneally for 14 days ( $n=7 /$ group)

\begin{tabular}{l|c|c|c|c|}
\hline GROUPS & BDNF & CREB & NGF & Synapsin \\
\hline Cont.+Clo. & $1.981 \uparrow$ & $3.553 \uparrow$ & $1.762 \uparrow$ & $6.242 \uparrow$ \\
\hline Cont.+Ola. & $1.424 \downarrow$ & $2.018 \downarrow$ & $2.013 \uparrow$ & $6.552 \uparrow$ \\
\hline $\begin{array}{l}\downarrow \text { decrease in expression; } \uparrow \text { increase in expression; CREB: cyclic adenosine monophosphate response element binding protein; BDNF: brain-derived neurotrophic } \\
\text { factor; NGF: nerve growth factor; FGF2: fibroblast growth factor 2; Clo.: clozapine; Ola.: olanzapine; Cont.: control }\end{array}$
\end{tabular}




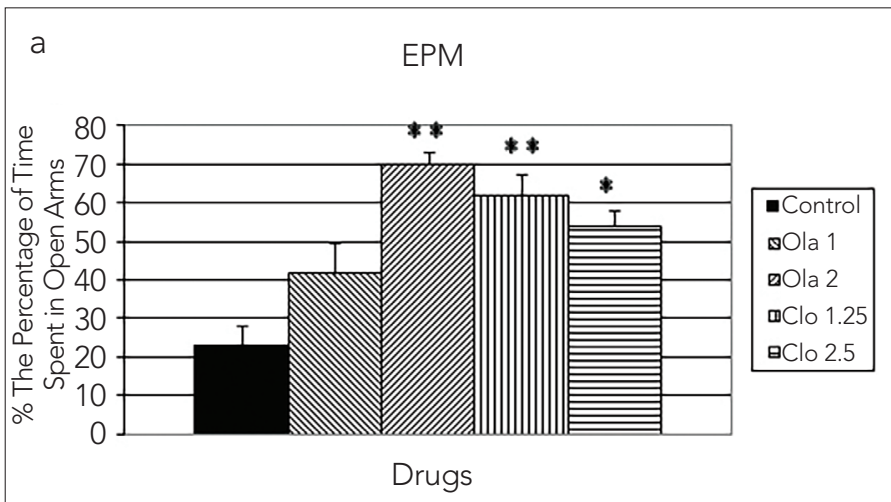

b EPM

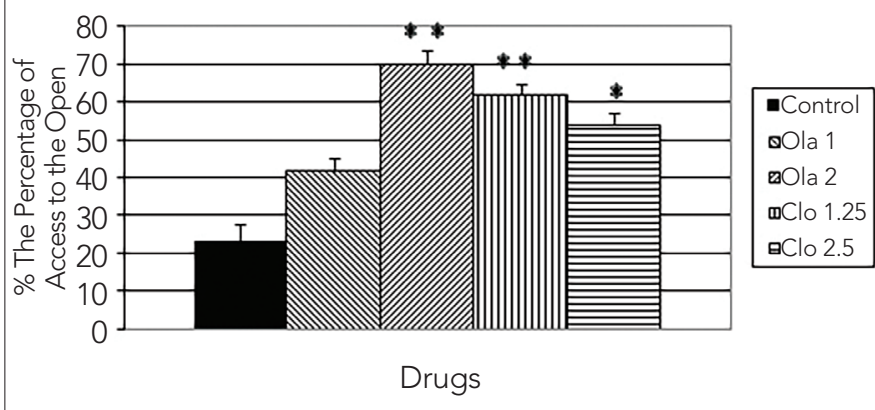

Figure 2. a, b. Effects of olanzapine ( 1 and $2 \mathrm{mg} / \mathrm{kg} ; \mathrm{n}=9$ and 10 , respectively) and clozapine $(1.25$ and $2.5 \mathrm{mg} / \mathrm{kg} ; \mathrm{n}=8$ and 10, respectively) administered intraperitoneally 10 days in the EPM test on (a) the percentage of time spent in open arms and (b) percentage of access to the open arms. Data are expressed as mean \pm standard deviation $\left({ }^{\star} p<0.01,{ }^{\star \star} p<0.001\right.$ compared to the control group)

(EPM: elevated plus maze; Clo.: clozapine; Ola.: olanzapine)

drites, and histopathophysiological changes in the volume and structure of important brain areas, such as the hippocampus, amygdala, prefrontal cortex, and striatum (17). All these changes lead to suicidal ideation, depression, anxiety, and learning-memory disorders. Olanzapine and clozapine are atypical antipsychotic drugs that are commonly used in the clinic, and atypical antipsychotics are known to be better at restoring the aforementioned symptoms compared to the classic antipsychotics.

Due to the reported antidepressant and anxiolytic effects of some antipsychotics, we investigated the effect of olanzapine and clozapine on depression and anxiety and the neurotrophic factors involved in this effect. In previous studies, it has been reported that haloperidol, a classical antipsychotic, increased the time of inactivity in FST (18) and increased the diazepaminduced anxiolytic effect in the EPM test (19). In other studies, clozapine and olanzapine have been reported to shorten the immobility time in FST (18); clozapine had no effect on anxiety (20); and olanzapine showed anxiolytic-like effect in the EPM test (21). Risperidone did not alter the time of inactivity in FST in low doses but increased the activity of antidepressants (22). Risperidone or fluoxetine showed anxiolytic-like effect in the EPM test (21). Quetiapine may be added to the antidepressant treatment in treatment-resistant depression (23); it was reported to increase the time spent in the open arms and the open arm access in the EPM test (24). Cyamemazine has an anxiolytic effect in EPM (25). Ziprasidone showed antidepressant and anxiolytic effects $(26,27)$. All these results support the healing effects of atypical antipsychotics on the negative symptoms of schizophrenia. In our study, clozapine showed both antidepressant and anxiolytic effects, whereas olanzapine showed only anxiolytic effects.

Schizophrenia and psychotic disorders are known to cause changes in the expression of neurotrophic factors, such as BDNF, in the hippocampal neurons $(6-8,11)$. In our study, clozapine increased the expression of all neurotrophic factors in a way that explains the antidepressant and anxiolytic effect in behavioral tests. In contrast, olanzapine increased the expression of NGF, synapsin, and FGF2 and decreased BDNF and CREB expression. $\mathrm{BDNF}$, a neurotrophin family member, plays an important role in the development, regeneration, and sustainability of neuronal functions in the central nervous system (7). A change in the hippocampal BDNF expression is associated with an antidepressant response in the hippocampus. The increase in the expression levels of this neurotrophic factor may explain the antidepressant and anxiolytic effects of clozapine. The decrease in hippocampal BDNF and CREB levels after the administration of chronic olanzapine may justify the absence of antidepressant effects of olanzapine in our study. The increase in NGF, synapsin, and FGF2 expression levels due to olanzapine may explain the anxiolytic effects of olanzapine.

\section{CONCLUSION}

Clozapine showed both antidepressant and anxiolytic effects compared to olanzapine. However, olanzapine showed an anxiolytic effect at the doses administered in our study and had no antidepressant effect. In addition, clozapine increased all neurotrophic factors in the rat hippocampus, whereas olanzapine decreased BDNF and CREB expression. These results suggest that clozapine is a more effective treatment option for the correction of negative symptoms of schizophrenia and psychosis compared to olanzapine.

Ethics Committee: Ethics approval for this study was granted by the Kocaeli University Ethics Committee (Number: AEK 1/6/2014, Kocaeli, Turkey) and all procedures involving animals were in compliance with the European Community Council Directive of 24 November 1986.

Informed Consent: N/A.

Peer-review: Externally peer-reviewed.

Author Contributions: Concept - E.G., O.M; Design - E.G., O.M; Supervision - E.G., O.M; Resources - E.G., O.M.; Materials - O.M., E.G.; Data Collection and/or Processing -O.M., E.G; Analysis and/or Interpretation - E.G., O.M.; Literature Search - E.G., O.M.; Writing Manuscript - O.M., E.G.; Critical Review - E.G., O.M.

Conflict of Interest: The authors have no conflict of interest to declare.

Financial Disclosure: The authors declared that this study has received no financial support. 


\section{REFERENCES}

1. Nandra KS, Agius M. The differences between typical and atypical antipsychotics: the effects on neurogenesis. Psychiatr Danub 2012; 24: 95-9.

2. Fulton B, Goa KL. Olanzapine. A review of its pharmacological properties and therapeutic efficacy in the management of schizophrenia and related psychoses. Drugs 1997; 53: 281-98. [CrossRef]

3. Seeman P. Atypical antipsychotics: mechanism of action. Can J Psychiatry 2002; 47: 27-38. [CrossRef]

4. Bymaster FP, Calligaro DO, Falcone JF, Marsh RD, Moore NA, Tye $\mathrm{NC}$, et al. Radioreceptor binding profile of the atypical antipsychotic olanzapine. Neuropsychopharmacology 1996; 14: 87-96. [CrossRef]

5. Coward DM. General pharmacology of clozapine. Br J Psychiatry 1992; 160: 5-11. [CrossRef]

6. Fumagalli F, Molteni R, Bedogni F, Gennarelli M, Perez J, Racagni G, et al. Quetiapine regulates FGF-2 and BDNF expression in the hippocampus of animals treated with MK-801. Neuroreport 2004; 15 : 2109-12. [CrossRef]

7. Martinotti G, Di lorio G, Marini S, Ricci V, De Berardis D, Di Giannantonio M. Nerve growth factor and brain-derived neurotrophic factor concentrations in schizophrenia: a review. J Biol Regul Homeost Agents 2012; 26: 347-56.

8. Branchi I, Francia N, Alleva E. Epigenetic control of neurobehavioural plasticity: the role of neurotrophins. Behav Pharmacol 2004; 15: 353-62. [CrossRef]

9. Halim ND, Weickert CS, McClintock BW, Weinberger DR, Lipska BK. Effects of Chronic Haloperidol and Clozapine Treatment on Neurogenesis in the Adult Rat Hippocampus. Neuropsychopharmacology 2004; 29: 1063-9. [CrossRef]

10. Garcia LS, Comim CM, Valvassori SS, Réus GZ, Andreazza AC, Stertz $L$, et al. Chronic Administration of Ketamine Elicits AntidepressantLike Effects in Rats without Affecting Hippocampal Brain-Derived Neurotrophic Factor Protein Levels. Basic Clin Pharmacol Toxicol 2008; 103: 502-6. [CrossRef]

11. Xua H, Qinga H, Lub W, Keegana D, Richardsonc JS, Chlan-Fourneya $J$, et al. Quetiapine attenuates the immobilization stress-induced decrease of brain-derived neurotrophic factor expression in rat hippocampus. Neuroscience Letters 2002; 321: 65-8. [CrossRef]

12. Skarsfeldt T. Differential effect of antipsychotics on place navigation of rats in the Morris water maze. Psychopharmacology 1996; 124: 126-33. [CrossRef]

13. Didriksen M, Kreilgaard M, Arnt J. Sertindole, in contrast to clozapine and olanzapine, does not disrupt water maze performance after acute or chronic treatment. Eur J Pharmacol 2006; 542: 108-15. [CrossRef]

14. Porsolt RD, Bertin A, Jalfre M. Behavioral despair in mice: a primary screening test for antidepressants. Arch Int Pharmacodyn Ther 1977; 229: 327-36.
15. Savlı H, Aalto Y, Nagy B, Knuutila S, Pakkala S. Gene expression analysis of 1,25(OH)2D3-dependent differentiation of HL-60 cells: a cDNA array study. Br J Haematol 2002; 118: 1065-72. [CrossRef]

16. Savlı H, Karadenizli A, Kolaylı F, Gundes S, Ozbek U, Vahaboglu H. Expression stability of six housekeeping genes: A proposal for resistance gene quantification studies of Pseudomonas aeruginosa by real-time quantitative RT-PCR. J Med Microbiol 2003; 52: 403-8. [CrossRef]

17. Halim ND, Weickert CS, McClintock BW, Weinberger DR, Lipska BK. Effects of Chronic Haloperidol and Clozapine Treatment on Neurogenesis in the Adult Rat Hippocampus. Neuropsychopharmacology 2004; 29: 1063-9. [CrossRef]

18. Weiner I, Schiller D, Gaisler-Salomon I, Green A, Joel D. A comparison of drug effects in latent inhibition and the forced swim test differentiates between the typical antipsychotic haloperidol, the atypical antipsychotics clozapine and olanzapine, and the antidepressants imipramine and paroxetine. Behav Pharmacol 2003; 14: 215-22. [CrossRef]

19. Taukulis HK1, Fillmore MT, Ruggles JL. Neuroleptic-induced changes in the anxiolytic and myorelaxant properties of diazepam in the rat. Pharmacol Biochem Behav 1992; 41: 13-21. [CrossRef]

20. Cao BJ, Rodgers RJ. Dopamine D4 receptor and anxiety: behavioural profiles of clozapine, L-745,870 and L-741,742 in the mouse plus-maze. Eur J Pharmacol 1997; 24: 117-25. [CrossRef]

21. Rogóż Z, Skuza G. Anxiolytic-like effects of olanzapine, risperidone and fluoxetine in the elevated plus-maze test in rats. Pharmacol Rep 2011; 63: 1547-52. [CrossRef]

22. Rogóz Z, Kabzi-ski M. Enhancement of the antiimmobility action of antidepressants by risperidone in the forced swimming test in mice. Pharmacol Rep 2011; 63: 1533-8. [CrossRef]

23. Wang Y, Chang T, Chen YC, Zhang RG, Wang HN, Wu WJ, et al. Quetiapine add-on therapy improves the depressive behaviors and hippocampal neurogenesis in fluoxetine treatment resistant depressive rats. Behavioural Brain Research 2013; 253: 206-11. [CrossRef]

24. McLelland AE, Martin-Iverson MT, Beninger RJ. The effect of quetiapine (Seroquel ${ }^{\mathrm{TM}}$ ) on conditioned place preference and elevated plus maze tests in rats when administered alone and in combination with (+)-amphetamine. Psychopharmacology 2014; 231: 4349-59. [CrossRef]

25. Bourin M, Dailly E, Hascöet M. Preclinical and clinical pharmacology of cyamemazine: anxiolytic effects and prevention of alcohol and benzodiazepine withdrawal syndrome. CNS Drug Rev 2004; 10: 21929. [CrossRef]

26. Rajkumar R, Pandey DK, Mahesh R, Radha R. 1-(m-Chlorophenyl)piperazine induces depressogenic-like behaviour in rodents by stimulating the neuronal 5-HT2A receptors: Proposal of a modified rodent antidepressant assay. Eur J Pharmacol 2009; 608: 32-41. [CrossRef]

27. Wilner KD, Anziano RJ, Johnson AC, Miceli JJ, Fricke JR, Titus CK. The anxiolytic effect of the novel antipsychotic ziprasidone compared with diazepam in subjects anxious before dental surgery. J Clin Psychopharmacol 2002; 22: 206-10. [CrossRef] 